\title{
Medical Utilization Rate at Music Festivals: The Effect of Crowd Behavior
}

\author{
George A. Fidacaro, Jr. MD; $\odot$ Matt S. Friedman, MD; Reuben J. Strayer, MD
}

\author{
Department of Emergency Medicine, \\ Maimonides Medical Center, Brooklyn, New \\ York USA \\ Correspondence: \\ George Fidacaro, MD \\ 4802 Tenth Avenue \\ Brooklyn, New York 11219 USA \\ E-mail: gfidacaro@maimonidesmed.org
}

Conflicts of interest/funding: All authors declare no relevant conflicts of interest. There are no sources of support, equipment, drugs, or grants to declare.

Keywords: crowd behavior; EMS; event medicine; mass-gathering medicine; toxicology

Abbreviations:

EDMF: electronic dance music festival

LSD: lysergic acid diethylamide

MDMA: 3,4-methylenedioxymethamphetamine

MUR: medical utilization rate

PPR: patient presentation rate

TTHR: transfer-to-hospital rate

Received: July 12, 2021

Accepted: July 24, 2021

\section{doi:10.1017/S1049023X21000960}

(C) The Author(s), 2021. Published by

Cambridge University Press on behalf of the

World Association for Disaster and Emergency Medicine.
Fidacaro GA Jr., Friedman MS, Strayer RJ. Medical utilization rate at music festivals: the effect of crowd behavior. Prehosp Disaster Med. 2021;36(6):803-804.

Electronic dance music festivals (EDMFs) are rising in popularity but have gained notoriety due to an alarming incidence of hospitalizations and deaths. ${ }^{1,2}$ In order to estimate needed resources, mass-gathering medicine literature has focused on predicting medical utilization at these events. Indicators of medical utilization rates (MURs) include frequency of patient presentation to medical attention and ambulance transport to hospital. Commonly used variables thought to influence MUR include event type and duration, temperature, geographic location (indoor versus outdoor), crowd type and behavior, and alcohol and drug use. ${ }^{3,4}$ Previously described experience at similar events has been shown to accurately predict future needs. ${ }^{5}$ The National Association for EMS Physicians (NAEMSP; Overland Park, Kansas USA) has incorporated these factors into guidelines to help medical directors allocate resources and design risk mitigation tactics. ${ }^{5}$ However, there are currently no evidenced-based recommendations regarding optimal allotment of assets at musical festivals.

We collected data on consecutive patients presenting for medical attention at two large outdoor music festivals in New York City (New York USA). Festival A was an EDMF while Festival B included an array of music genres that included rock and pop; electronic music was not featured at Festival B. The daily outdoor heat index for Festival A was $19^{\circ} \mathrm{C}-36^{\circ} \mathrm{C}\left(67^{\circ} \mathrm{F}-\right.$ $\left.96^{\circ} \mathrm{F}\right)$ and for Festival $\mathrm{B}$ was $11^{\circ} \mathrm{C}-23^{\circ} \mathrm{C}\left(52^{\circ} \mathrm{F}-73^{\circ} \mathrm{F}\right)$. We evaluated the difference in MURs between the two festivals by measuring patient presentation rates (PPRs) and transfer-to-hospital rates (TTHRs).

Festival A had a three-day attendance of 75,000 with 173 presentations for medical attention, resulting in a PPR of 23 per 10,000 attendees. Eight patients were transported to the hospital, resulting in a TTHR rate of 1.06. Festival B had a three-day attendance of 120,000 with 126 patient presentations, resulting in a PPR of 10.5 . Four patients required transport, resulting in a TTHR of 0.33 . Thus, despite a much higher attendance at Festival $\mathrm{B}$, the EDMF had a higher MUR and a higher TTHR.

The percentage of reported recreational drug use at Festivals $\mathrm{A}$ and at Festival B are displayed in Figure 1. At Festival A, 3,4-methylenedioxymethamphetamine (MDMA; Molly, Ecstasy) was most commonly reported, whereas marijuana was most commonly reported at Festival B. Compared to Festival B, patients at Festival A presented with higher systolic blood pressures, respiratory rates, and heart rates; Festival A attendees were also more likely to have dilated pupils and diaphoretic skin.

Recreational drugs used at festivals tend to be entactogens: psychostimulants that produce experiences of emotional communion and openness, such as MDMA and lysergic acid diethylamide (LSD; acid). The sympathomimetic properties of MDMA elevate the body's core body temperature while its euphoric qualities both encourage increased physical activity and distract the user from resulting potentially dangerous hyperthermia. Toxicity from MDMA may also cause hyponatremia, seizures, rhabdomyolysis, hyperkalemia, acidosis, multi-organ failure, and death. The hallucinogenic effects of LSD produce heightened sensory perception, euphoria, and sense of well-being, with users commonly describing out-of-body experiences or synesthesia. While hemodynamic and metabolic derangements are less common with LSD intoxication, LSD can precipitate serotonin syndrome and can cause dangerous behaviors based on hallucinatory or delusional beliefs (eg, that the user can fly). The wide-spread use of these drugs at an EDMF affects behavior by creating an energetic and active crowd, which may increase MURs.

Music festivals create a high MUR with a range of illness severity affecting an otherwise healthy population. On-site medical teams should anticipate a higher PPRs and TTHRs at 


\section{Comparison of Drug Use}

nfestivalA = Festival B

60

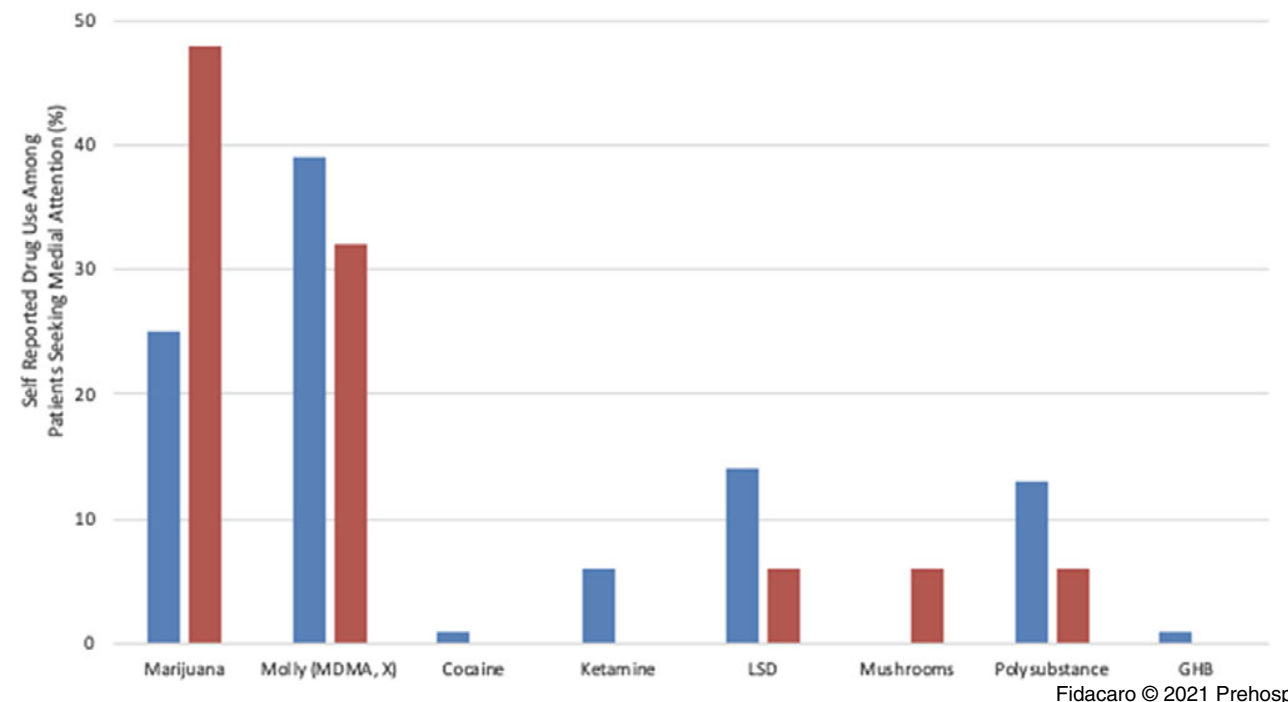

Figure 1. Self-Reported Drug Use Among Patients Presenting for Medical Attention (\%).

Abbreviations: LSD, lysergic acid diethylamide; MDMA, 3,4-methylenedioxymethamphetamine; GHB, gamma hydroxybutyrate.

an EDMF, likely attributable to crowd behavior and the common use of recreational stimulants, potentially compounded by exertional heat illness. Further work should focus on improving prospective prediction methods to adequately assess needs such that local health care resources are not diverted from the usual care they provide for the hosting community.

\section{References}

1. Ridpath A, Driver CR, Nolan ML, et al. Illnesses and deaths among persons attending an electronic dance-music festival- New York City, 2013. MMWR Morb Mortal Wkly Rep. 2014;63(50):1195-1198.

2. Friedman MS, Plocki A, Likourezos A, et al. A prospective analysis of patients presenting for medical attention at a large electronic dance music festival. Prehosp Disaster Med. 2017;32(1):78-82.

3. Arbon P. Mass gathering medicine: a review of the evidence and future directions for research. Prehosp Disaster Med. 2007;22(2):131-135.

4. Perron AD, Brady WJ, Custalow CB, Johnson DM. Association of heat index and patient volume at a mass gathering event. Prehosp Emerg Care. 2005;9(1): 49-52.

5. Schwartz B, Nafziger S, Milsten A, Luk J, Yancey A II. Mass gathering medical care: resource document for the National Association of EMS Physicians position statement. Prehosp Emerg Care. 2015;19(4):559-568. 